\title{
Some Effects of Oxygen on the Growth and Physiology of Selenomonas ruminantium
}

\author{
By JULIAN W. T. WIMPENNY AND OTHMAN A. SAMAH \\ Department of Microbiology, University College, \\ Newport Road, Cardiff CF2 1TA
}

(Received 28 May 1978)

\section{INTRODUCTION}

All microorganisms are sensitive to molecular oxygen at some partial pressure (Haugaard, 1968; Morris, 1975). The term 'obligate anaerobe' embraces a wide spectrum of sensitivities from those species that are aerotolerant under certain conditions to very strict anaerobes that are killed by minute traces of oxygen. The low solubility of oxygen in aqueous media ensures that many environments are inhabited by predominantly anaerobic organisms. Such environments include the soil, marine and freshwater sediments and most body cavities including the rumen of herbivores. Since many of these organisms may at some time encounter oxygen, their response to this strong oxidant is of great interest.

The mechanisms of oxygen toxicity have been reviewed by Morris (1975). It is possible that oxygen itself is a toxic agent perhaps by acting as an alternative electron acceptor depriving the cell of reductant for biosynthetic reactions. It may oxidize labile thiol groups, for example those present in low-potential carriers such as ferredoxin, or inactivate specific enzymes, such as nitrogenase in nitrogen-fixing bacteria. Oxygen may be toxic as one of its metabolites; these include singlet oxygen, the superoxide anion, hydrogen and the hydroxyl free radical. The absence of catalase from anaerobes led McLeod \& Gordon (1923) to suggest that hydrogen peroxide was the toxic agent; however, recent evidence, reviewed by Morris (1975), casts some doubt on this explanation. McCord et al. (1971) proposed that the absence of the enzyme superoxide dismutase accounted for the sensitivity of anaerobes to oxygen. However, recent evidence from several laboratories (Hewitt \& Morris, 1975; Shoesmith \& Ashley, 1977; Tally et al., 1977) has indicated that this enzyme is present in various anaerobes.

The phenomenon of anaerobiosis itself has drawn attention away from possible oxygen protective mechanisms that might be present in these cells. The first such mechanism was reported by O'Brien \& Morris (1971) who demonstrated that Clostridium acetobutylicum had a marked capacity to reduce oxygen using an oxygen-inducible NADH oxidase. Only when oxygen provision exceeded the capacity of the cell to reduce it was cell growth inhibited.

It seems likely that oxygen toxicity is not due to any single all-embracing mechanism and also that many anaerobes have sophisticated mechanisms designed to detoxify it. The research presented here illustrates the response of an anaerobic, Gram-negative, curved, rod-shaped bacterium, Selenomonas ruminantium, to changes in oxygen tension in batch cultures.

\section{METHODS}

Maintenance and growth of Selenomonas ruminantium. Selenomonas ruminantium (from the Rowett Research Institute collection) was maintained in stab cultures on casitone (Difco)/glucose/yeast extract (Difco) medium solidified with $2 \%(\mathrm{w} / \mathrm{v})$ agar. Inocula were incubated anaerobically in $200 \mathrm{ml}$ growth medium in screw-capped medical flats for $48 \mathrm{~h}$ at $37^{\circ} \mathrm{C}$. The growth medium contained $\left(\mathrm{g} \mathrm{l}^{-1}\right)$ : Bactocasitone, $10 ;$ yeast extract, $2 \cdot 5 ; \mathrm{K}_{2} \mathrm{HPO}_{4}, 3 ; \mathrm{KH}_{2} \mathrm{PO}_{4}, 3 ;\left(\mathrm{NH}_{4}\right)_{2} \mathrm{SO}_{4}, 6 ; \mathrm{NaCl}, 6 ; \mathrm{MgSO}_{4} .7 \mathrm{H}_{2} \mathrm{O}, 0.6 ;$ glucose, 6 ; $\mathrm{NaHCO}_{3}, 4 ; \mathrm{CaCl}_{2}, 0.6$; cysteine. $\mathrm{HCl}, 0 \cdot 5$. The medium was sterilized in 81 batches by autoclaving at $121^{\circ} \mathrm{C}$ 
for $20 \mathrm{~min}$ in a 101 fermenter vessel (L.H. Engineering Co., Stoke Poges, Bucks). Cultures were grown at $37^{\circ} \mathrm{C}$ with continuous stirring at $57 \mathrm{rev}$. $\mathrm{min}^{-1}$. The medium was sparged with $\mathrm{H}_{2} / \mathrm{CO}_{2}(95: 5$, v/v) for $5 \mathrm{~min}$ before inoculation and with purified nitrogen thereafter. When the absorbance of the culture reached a predetermined point, various quantities of air were introduced into the gas mixture using either a calibrated peristaltic pump (Watson-Marlow MHRE, Falmouth, Cornwall) or a rotameter (Meterate GPE, Hemel Hempstead, Herts). Samples were taken at regular intervals for microscopic examination and for purity plating. Absorbance was read against uninoculated media in $3 \mathrm{ml}$ cuvettes at $550 \mathrm{~nm}$.

Preparation of extract. Cells were harvested using a continuous flow centrifuge (LAB 102 B25; Alfa Laval Co., Brentford, Middlesex) and were washed twice in $20 \mathrm{mM}-\mathrm{KH}_{2} \mathrm{PO}_{4} / \mathrm{KOH}$ buffer (pH 7.0) before being disrupted in a Hughes (1951) press cooled to $-24^{\circ} \mathrm{C}$. The crude broken material was centrifuged first at $34000 \mathrm{~g}$ for $20 \mathrm{~min}$ and then at $85000 \mathrm{~g}$ for $60 \mathrm{~min}$ to give particulate fractions and a substantially particle-free supernatant.

Respiration measurement and enzyme assays. Oxygen uptake was measured polarographically in washed whole-cell suspensions using a Clark-type oxygen electrode (Rank Electrodes, Bottisham, Cambs). The electrode compartment contained cells suspended in $3 \mathrm{ml} 20 \mathrm{mM}-\mathrm{KH}_{2} \mathrm{PO}_{4} / \mathrm{KOH}$ buffer (pH 7.4); $25 \mu \mathrm{mol}$ glucose was added after establishing an endogenous rate.

NADH oxidase was assayed spectrophotometrically by following the oxidation of $50 \mu \mathrm{M}-\mathrm{NADH}$ at $340 \mathrm{~nm}$ in $20 \mathrm{mM}-\mathrm{KH}_{2} \mathrm{PO}_{4} / \mathrm{KOH}$ buffer (pH 7.4). NADH peroxidase activity was examined by adding $50 \mu \mathrm{mol} \mathrm{H}_{2} \mathrm{O}_{2}$ near the end of the NADH oxidase assay. Assay volumes were $3.0 \mathrm{ml}$.

To confirm the absence of $\mathrm{NADH}$ peroxidase in the preparation, catalase was added to some NADH oxidase assays. No inhibition in the rate of NADH oxidation was observed. Superoxide dismutase was assayed by the method of Beauchamp \& Fridovich (1971). Various quantities of supernatant were used and the level of inhibition of nitroblue tetrazolium reduction relative to the rate of reduction of a control was plotted against protein concentration. The enzyme activity was expressed as the reciprocal of the concentration of protein required to give $50 \%$ inhibition.

Protein was estimated by the method of Lowry et al. (1951) with bovine serum albumin as standard.

Chemicals. NADH and nitroblue tetrazolium were obtained from Sigma. Bovine serum albumin was obtained from Armour Pharmaceuticals, Eastbourne, Sussex. All other chemicals were of analytical reagent grade.

\section{RESULTS AND DISCUSSION}

\section{Oxygen and the growth of $S$. ruminantium}

Anaerobic cultures of $S$. ruminantium were grown to an absorbance of between 0.8 and 1.0 before harvesting. All the cultures receiving oxygen were grown anaerobically to an absorbance of 0.3 to 0.5 and the gas mixture was then changed to include different partial pressures of oxygen. The maximum specific growth rate for the organism grown anaerobically was $0.75 \mathrm{~h}^{-1}$. Oxygen addition up to a partial pressure of $46 \mathrm{mmHg}(1 \mathrm{mmHg}=1.33$ $\mathrm{kPa}$ ) had little effect on growth rate. Growth was inhibited at $77 \mathrm{mmHg}$ and complete growth inhibition ensued at partial pressures of 94 and $110 \mathrm{mmHg}$ (Fig. 1). Apart from the two cultures showing severe growth inhibition, the cultures were harvested at the end of their normal growth period when the absorbance was 0.8 or higher. The inhibited cultures were incubated for the period indicated in Fig. 1 before harvesting.

As shown by O'Brien \& Morris (1971) for Clostridium acetobutylicum, considerable amounts of oxygen may be passed into growing cultures of an anaerobic bacterium with no obvious deleterious effects. This seems also to be the case with $S$. ruminantium.

\section{Respiration of washed cells of $S$. ruminantium}

The capacity for whole cells to reduce oxygen was tested using an oxygen electrode. When cells were exposed to partial pressures of oxygen that did not significantly inhibit growth, there was a very significant rise in respiration rate (Fig. $2 a$ ). Both the endogenous respiration rate and respiration with glucose as a substrate were affected in the same way. Where oxygen toxicity was evident, the respiration rates for the cells fell and were zero at the highest oxygen partial pressure tested. The fall can be explained either as direct inhibition of respiration or as inhibition of the induction process responsible for the large rise in respiration rates at lower oxygen tensions. Clearly an inducible respiratory system in S. ruminantium could operate as an effective oxygen scavenging device. 


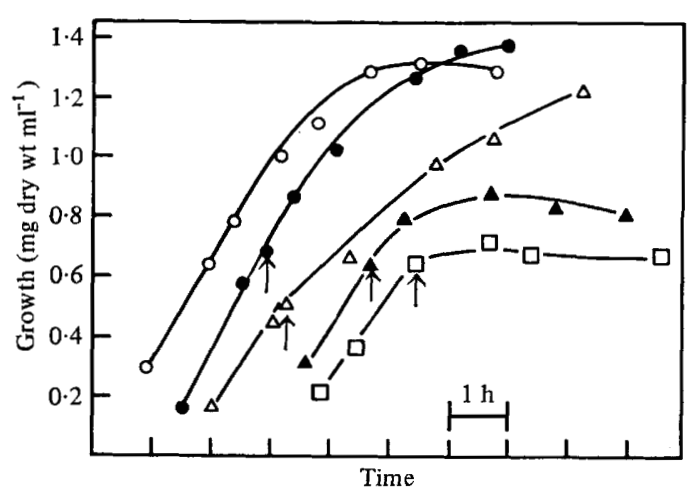

Fig. 1. Growth of Selenomonas ruminantium in the presence of different partial pressures of oxygen (in $\mathrm{mmHg}$ ): $\bigcirc, 0 ; 0,45.9 ; \triangle, 76.5 ; \Delta, 94.8 ; \square, 110.2$. The arrows indicate the times at which oxygen was added to the gas mixtures.

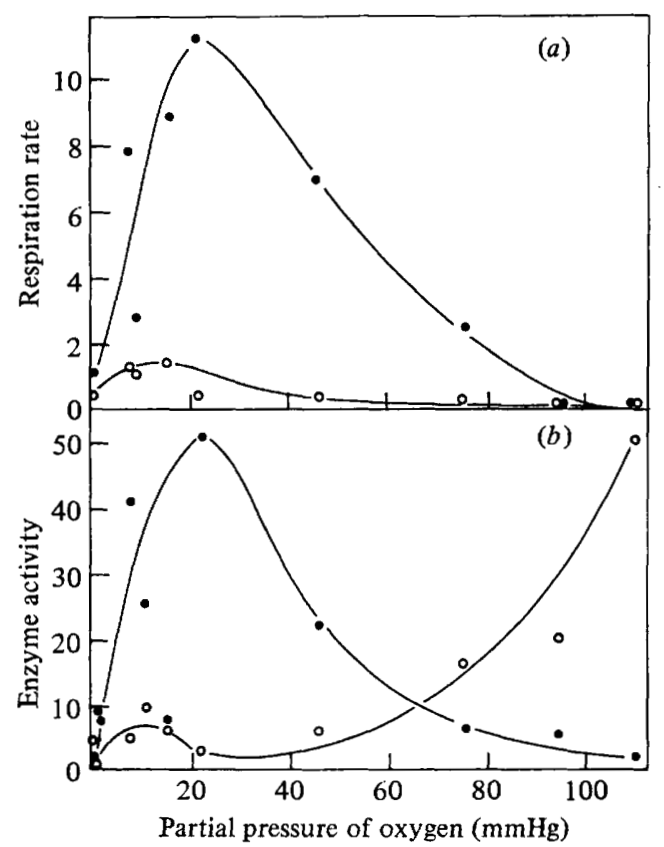

Fig. 2. Respiration rates in, and enzyme activities in extracts from, $S$. ruminantium grown in the presence of different partial pressures of oxygen. $(a)$ Respiration rates [nmol $\mathrm{O}_{2}\left(\mathrm{mg}\right.$ dry cells) ${ }^{-1}$ min $^{-1}$ ]: $\bigcirc$, endogenous; $O$, with glucose. (b) Enzyme activities in cell-free extracts: $\bullet$, NADH oxidase [nmol NADH (mg protein $\left.)^{-1} \mathrm{~min}^{-1}\right] ; 0$, superoxide dismutase [(mg protein for $50 \%$ inhibition) ${ }^{-1}$.

\section{Enzyme activities in cell-free extracts}

NADH oxidase, NADH peroxidase and superoxide dismutase activities were measured in each cell-free extract (particulate fraction and supernatant). No detectable NADH peroxidase was measured at any oxygen partial pressure. NADH oxidase activity was induced by oxygen and followed the same pattern as changes in cell respiration rate (Fig. $2 b$ ). The enzyme activity was present only in the high-speed supernatant fraction indicating that the enzyme is soluble and, by analogy with other soluble NADH oxidases, probably a flavoprotein. It seems reasonable to conclude that $S$. ruminantium contains an oxygen- 
inducible NADH oxidase which can be coupled to glucose catabolism to scavenge oxygen from the environment. Above a certain partial pressure of oxygen the system can no longer cope with this toxic agent; growth is inhibited and NADH oxidase activity and respiration rates drop. These results confirm the observations of O'Brien \& Morris (1971) with $\mathrm{Cl}$. acetobutylicum and of Shoesmith \& Ashley (1977) with other species of clostridia. Thus the Gram-negative anaerobe $S$. ruminantium behaves in a similar fashion to Grampositive species already examined.

The behaviour of superoxide dismutase is interesting: regulation of this enzyme may complement the behaviour of NADH oxidase (Fig. $2 b$ ). Two points must be made. First, $S$. ruminantium clearly shows superoxide dismutase activity. This adds to the growing body of evidence that strict anaerobes do possess the enzyme and suggests that an explanation for obligate anaerobiosis proposed by McCord et al. (1971) based on the absence in anaerobes of superoxide dismutase is an oversimplification. Secondly, the enzyme is inducible though it responds to higher oxygen partial pressures than NADH oxidase activity. Interestingly, the highest levels were found in cells whose growth was completely inhibited by oxygen. Whether de novo protein synthesis occurs under these conditions or whether pre-existing protein is converted to active enzyme is open to speculation. Superoxide dismutase may be formed in response to accumulating superoxide anion and this would probably only be formed when free oxygen was present; in other words, at levels beyond the ability of the inducible NADH oxidase activity to cope.

The authors would like to thank Dr Colin Henderson of the Rowett Research Institute, Aberdeen, for kindly supplying the culture of Selenomonas ruminantium.

\section{REFERENCES}

Beauchamp, C. \& Fridovich, I. (1971). Superoxide dismutase: improved assays and an assay applicable to acrylamide gel. Analytical Biochemistry 44, 276-287.

HaugaARD, N. (1968). Cellular mechanisms of oxygen toxicity. Physiological Reviews 48, 311-373.

HewitT, J. \& MorRIS, J. G. (1975). Superoxide dismutase in some obligately anaerobic bacteria. FEBS Letters 50, 315-318.

Hughes, D. E. (1951). A press for disrupting bacteria and other micro-organisms. British Journal of Experimental Pathology 32, 97-109.

Lowry, O. H., Rosebrough, N. J., FARR, A. L. \& RANDALl, R. J. (1951). Protein measurement with the Folin phenol reagent. Journal of Biological Chemistry 193, 265-275.

MCCord, J. M., KeEle, B. B., JR \& Fridovich, I. (1971). An enzyme based theory of obligate anaerobiosis, the physiological function of superoxide dismutase. Proceedings of the National Academy of Sciences of the United States of America 68, 1024-1027.
McLeod, J. W. \& Gordon, J. (1923). The problem of intolerance of oxygen by anaerobic bacteria. Journal of Pathology and Bacteriology 23, 332343.

Morris, J. G. (1975). The physiology of obligate anaerobiosis. Advances in Microbial Physiology 12, 169-246

O'Brien, R. W. \& Morris, J. G. (1971). Oxygen and the growth and metabolism of Clostridium acetobutylicum. Journal of General Microbiology 68, 307-318.

Shoesmith, J. G. \& Ashley, N. V. (1977). Continuous culture of Clostridium sporogenes and Clostridium bifermentans in the presence of oxygen. Proceedings of the Society for General Microbiology 4, 144.

TALLY, F. P., GoldIN, B. R., JACobus, N. V. \& Gorbach, S. L. (1977). Superoxide dismutases in anaerobic bacteria of clinical significance. Infection and Immunity 16, 20-25. 